\title{
Role of the Quartz Particles on Stain Resistance of the Polished Porcelain Tiles
}

\author{
N.T. Selli And A. Tunali \\ Eczacibasi Building Products Co., VitrA Innovation Center, Bozuyuk/Bilecik, Turkey
}

\begin{abstract}
In present study, effect of quartz particle size on microstructure and stain resistance of porcelain tiles were examined. Milling time was utilized as a main parameter to control residual quartz particle size. 12, 16 and 20 min milling time were used in a laboratory condition. As milling time increases, the particle size of residual quartz decreases. This reduction in the residual quartz particle size results in enhancement of the microstructure. When the microstructure contains irregular pores with high aspect ratio which are generally formed around the residual quartz in the body, stain resistance of the porcelain tiles decreases. Therefore, microstructural changes versus quartz particle size were investigated considering stain resistance of the polished porcelain tiles.
\end{abstract}

DOI: $10.12693 /$ APhysPolA.125.506

PACS: 81.05.Mh

\section{Introduction}

Porcelain stoneware tile is a product of excellent technical and broad aesthetic characteristics such as pressed relief, polishing, glazing etc. $[1,2]$. The unglazed porcelain tiles are usually undergone a polishing process and this process provides glossness on the product. However, this process decreases stain resistance of the tiles. In polished porcelain tiles, stain resistance is controlled by surface characteristics such as surface roughness, pore size, shape, and aspect ratio [3-5]. To increase the stain resistance, microstructure characteristics, in particular closed pore content, pore size, shape and aspect ratio should be controlled carefully to achieve high stain resistance. Especially this problem is related with irregular pores with high aspect ratio [6]. These type of pores play an important role for stain resistance and these pores decrease the stain resistance.

Generally, these types of pores are formed around the quartz particles as a result of thermal expansion mismatch as indicated Carty and Pinto [7]. In literature, there are some studies about controlling stain resistance with amount of quartz and grain size. Junior et al. [8] pointed the detachment of the quartz particles during polishing out as main factor, increasing surface porosity. Sanchez et al. [3] investigated utilization of quartz content in porcelain tile compositions. Starting from 6.25, $12.5,25,50 \mathrm{wt} \%$ quartz was added to compositions.

Increase of the quartz content in the compositions altered the microstructures of the porcelain tiles and it brought to rise in porosity with irregular shape. They also changed the quartz particle size which was added to initial composition. Two quartz samples were with a larger particle size (grit 6 and grit 10) and two quartz samples with a smaller particle size (grit 100 and 500). They reported that largest quartz grains displays a heterogeneous microstructure, which contains large sized pores and cracks mainly due to the presence of undissolved quartz particles in the glassy matrix.
However, the stain resistance of the compositions was not investigated in this study. In another study, Amoros et al. [9] changed the milling time of the reference porcelain tile composition. They investigated effect of green microstructure on the evaluation of porous texture during firing and fired product properties. They reported that the greater heterogeneity of the microstructure (when the green body contains large pores) was obtained in case of higher pore growth rate in less milled mixtures. They reported stain resistance decreases as degree of milling decreases.

However they did not explain relationship between stain resistance and residual quartz particle size which change by increases of the milling time of the composition. Although there are several studies about effect of milling time on microstructure development in porcelain stoneware tiles, these publications do not discuss how residual quartz particle size changes stain resistance of polished porcelain tile. Therefore, effect of residual quartz particle size on the microstructure and stain resistance of porcelain stoneware tiles should be investigated.

Consequently, the research objective of this study was to change residual quartz particle size and understand evaluate effect of the residual quartz particle size on densification, microstructure development, and hence stain resistance of porcelain stoneware tiles.

\section{Experimental procedure}

In this study, porcelain tile composition was prepared using industrially raw materials. The reference composition was denoted as (I). The chemical analysis of the composition was shown in Table I.

This composition was prepared by wet grinding. 3 suspensions (I-12, I-16, I-20) were prepared by milling this composition in a planetary ball mill for different times $(12,16,20 \mathrm{~min})$, in each case determining the residue on $45 \mu \mathrm{m}$ sieve. Particle size and distribution was determined by laser diffraction (Malvern Mastersizer 2000-G). Slips were dried at $110^{\circ} \mathrm{C}$. The powders obtained were 
TABLE I

Chemical compositions (wt\%) of porcelain stoneware body.

\begin{tabular}{c|c}
\hline \hline Compositions & $(\mathrm{I})$ \\
\hline $\mathrm{SiO}_{2}$ & $67-69$ \\
$\mathrm{Ti}_{2} \mathrm{O}$ & $0.45-0.60$ \\
$\mathrm{Al}_{2} \mathrm{O}_{3}$ & $19-23$ \\
$\mathrm{Fe}_{2} \mathrm{O}_{3}$ & $0.45-0.60$ \\
$\mathrm{MgO}$ & $0.10-0.50$ \\
$\mathrm{CaO}$ & $0.4-1$ \\
$\mathrm{Na} 2$ & $3.0-7.0$ \\
$\mathrm{~K}_{2} \mathrm{O}$ & $2.0-4.0$ \\
$\mathrm{P}_{2} \mathrm{O}_{5}$ & $0.01-1$ \\
lost of ignition & 3.5
\end{tabular}

moisturised with 5 wt\% water. The pellets with $50 \mathrm{~mm}$ diameter and $6 \mathrm{~mm}$ thickness were prepared by uniaxial pressing at a forming pressure of $44 \mathrm{bar}$ (Nannetti Press, Hydraulic Laboratory Press Mignon S, Italy). Optical dilatometer (Misura 3.32, ODHT-HSM, Expert System Solutions, Italy) was utilized to investigate sintering behaviour of the compositions as a function of temperature.

Sintering temperatures of the compositions were determined by flex point (i.e., temperature at which densification rate is maximum) analyses as stated by $\mathrm{Pa}-$ ganelli [10]. Samples were fired in roller furnace at $1220^{\circ} \mathrm{C}$ and 37 min. Staining was created by marking on the sample surface with permanent marker. After cleaning the surface with water, the colour variation value $(\Delta E)$ was measured by a spectrometer (Minolta $\mathrm{CR}, 300$ Colormeter). Staining agent was applied on the samples surfaces after polishing. Samples were polished by using polishing machine (Metkon-Forcipol-300-1N). The sample microstructures were examined by scanning electron microscopy (SUPRA-Zeiss-50VP, Germany) on the working surface of tiles, preliminary washed, dried and polished.

\section{Results and discussion}

Table II shows the residue data of the compositions on a $45 \mu \mathrm{m}$ sieve. As the milling time increases, the residue of the composition on $45 \mu \mathrm{m}$ sieve decreases directly.

TABLE II

Residue on the $45 \mu \mathrm{m}$ sieve of milled compositions.

\begin{tabular}{c|c|c}
\hline \hline Compositions & $\begin{array}{c}\text { Milling time } \\
{[\mathrm{min}]}\end{array}$ & $\begin{array}{c}\text { Residue on } 45 \mu \mathrm{m} \\
{[\mathrm{wt} \%]}\end{array}$ \\
\hline I-12 & 12 & $3.5 \pm 0.2$ \\
I-16 & 16 & $1.6 \pm 0.2$ \\
I-20 & 20 & $0.50 \pm 0.2$
\end{tabular}

As increases milling time, decrease the sintering temperatures of the composition. While the sintering point of the composition with $12 \mathrm{~min}$ is $1229^{\circ} \mathrm{C}$, the sintering point of the composition with $16 \mathrm{~min}$ is $1223^{\circ} \mathrm{C}$ and increases the milling time to $20 \mathrm{~min}$, and decreases the sintering point $1219^{\circ} \mathrm{C}$. These result is related with densification kinetics. Therefore high milling time decreases the sintering points of the compositions. Distributions of the particle size distribution of the compositions were represented in Table III. As milling time increases, size of the particles decreases. Effect of milling time on the residual quartz size was investigated by using scanning microscope.

TABLE III

Particle size distributions and flex points of the compositions dependence on the milling time.

\begin{tabular}{c|c|c|c|c}
\hline \hline Compositions & Flex points & $d(10)$ & $d(50)$ & $d(90)$ \\
\hline I-12 & $1229^{\circ} \mathrm{C}$ & 2.190 & 16.440 & 49.90 \\
I-16 & $1223^{\circ} \mathrm{C}$ & 2.070 & 8.985 & 35.197 \\
I-20 & $1219^{\circ} \mathrm{C}$ & 1.950 & 8.090 & 24.091
\end{tabular}

Figure 1 shows the effect of milling time on residual quartz particle size in the porcelain stoneware tile composition. As milling time increases, the residual quartz particle size decreases. While the milling time of the composition is $12 \mathrm{~min}$, quartz particle size is $34 \pm 2 \mu \mathrm{m}$, and when the milling time of the composition is $20 \mathrm{~min}$, the quartz particle size is $15 \pm 2 \mu \mathrm{m}$ in the porcelain stoneware tile composition.

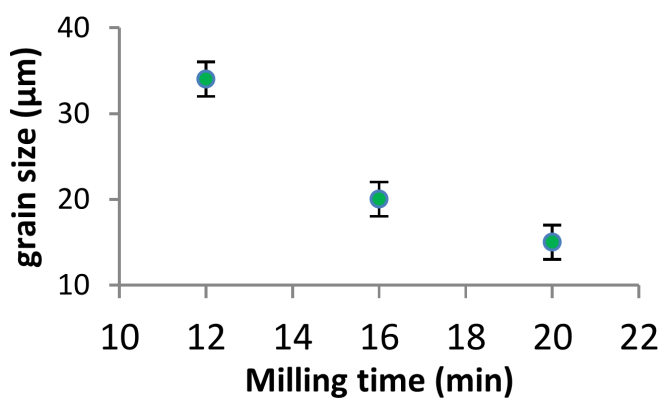

Fig. 1. Variation of residual quartz grain size dependence on the milling time.

The change in the residual quartz size brings to change the microstructure of the polished porcelain tile. Small quartz particle size due to the high milling time results in homogeneous microstructure favors spherical pore morphology which is so important for obtaining high stain resistant porcelain stoneware tiles $[5,6]$. Figure 2 shows the microstructural variation dependence on the milling time of the composition and raising of the milling time favors spherical pore morphology on the microstructure.

This variation in the microstructure results in high stain resistance (Fig. 3). The composition with low milling time (12 min) retains stain on the surface $(\Delta E>$ $10)$, on the other hand composition with high milling time $(20 \mathrm{~min})$ can be cleanable $(\Delta E<1)$. 


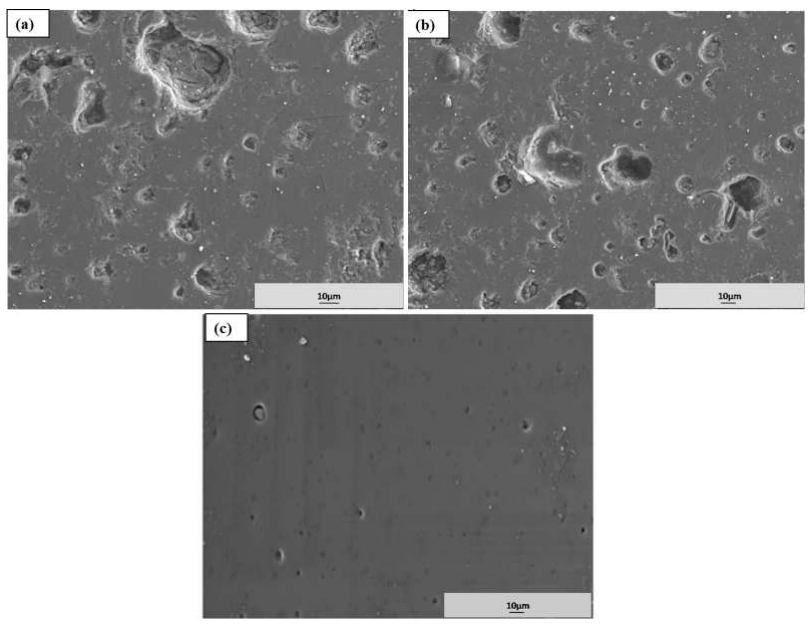

Fig. 2. Secondary electron micrographs of polished (I) samples dependence on the milling time: (a) $12 \mathrm{~min}$, (b) $16 \mathrm{~min}$, (c) $20 \mathrm{~min}$.

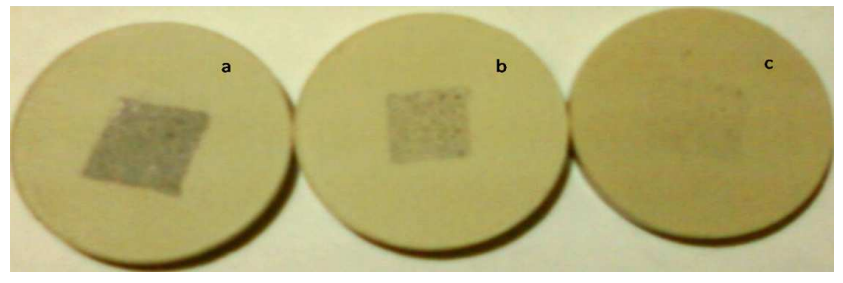

Fig. 3. Stain resistance of the polished samples against permanent marker after cleaning with water dependence on the milling time: (a) $12 \mathrm{~min}(\Delta E>10)$, (b) $16 \mathrm{~min}$ $(\Delta E>10)$, (c) $20 \min (\Delta E<1)$.

\section{Conclusions}

In this study, it has been found that milling time of the composition for determined recipe (I) affects the sintering temperature, residual quartz particle size, microstructural characteristics and stain resistance of the polished porcelain tile. Insufficient milling of composition of the porcelain tile cause the heterogeneity to the microstructure containing irregular shaped, large pores and coarse residual quartz particles. As the milling time increases, the residual quartz particle size decreases. This decrease plays important role for increasing the stain resistance of the tile body to decrease the pores with high aspect ratio. In this study $15 \pm 2 \mu \mathrm{m}$ residual quartz is acceptable limit for high stain resistant polished porcelain tile body for this composition.

\section{References}

[1] G. Nassetti, C. Palmonari, Ceram. Acta. 9, 15 (1997).

[2] L. Esposito, A. Tucci, E. Rastelli, C. Palmonari, S. Selli, Am. Ceram. Soc. Bull. 81, 38 (2002).

[3] E. Sanchez, M.J. Ibanez, J. Garcia-Ten, M.F. Quereda, I.M. Hutchings, Y.M. Xu, J. Eur. Ceram. Soc. 26, 2533 (2006).

[4] L. Esposito, A. Tucci, D. Naldi, J. Eur. Ceram. Soc. 25, 1487 (2005).

[5] M. Dondi, G. Ercolani, G. Guarini, C. Melandri, M. Raimondo, E.R. Almendra, P.M. Cavalante, J. Eur. Ceram. Soc. 25, 357 (2005).

[6] N. Tamsu, Ph.D. Thesis, Anadolu University, Turkey 2010.

[7] W.M. Carty, B.M. Pinto, Ceram. Eng. Sci. Proc. 23, 95 (2003).

[8] A.D.N. Junior, D. Hotza, V.C. Soler, E.S. Vilches, Mater. Sci. Eng. A 527, 1736 (2010).

[9] J.L. Amoros, M.J. Orts, J. Garcie-Ten, A. Gozalbo, E. Sanchez, J. Eur. Ceram. Soc. 27, 2295 (2007).

[10] M. Paganelli, Am. Ceram. Soc. Bull. 81, 25 (2002). 